\title{
EMPREENDEDORISMO IMIGRANTE E ÉTNICO: O PAPEL DAS REDES SOCIAIS NO PROCESSO EMPREENDEDOR DE UM IMIGRANTE SÍRIO NO BRASIL
}

Gislene Cordeiro da Silva Diniz ${ }^{1}$, Liliane de Oliveira Guimarães, Duval Magalhães Fernandes Pontifícia Universidade Católica de Minas Gerais - PUC, Minas Gerais, (Brasil).

\section{DETALHES DO ARTIGO}

\section{Histórico do Artigo:}

Recebido em: 21 de agosto de 2018

Aceito: 04 de março de 2019

Disponível online: 01 de abril de 2019

Sistema de revisão "Double blind review"

Editor Científico

Ilan Avrichir

\section{Palavras-chaves:}

Empreendedorismo Imigrante

Empreendedorismo Étnico

Redes Sociais

Imigrantes Sírios

\section{RESUMO}

Este estudo procurou compreender e analisar o papel das redes sociais no país de acolhimento no empreendedorismo de um imigrante sírio no Brasil. Com o uso da metodologia "história de vida", buscou-se identificar e descrever os tipos de recursos que são oferecidos pelas redes sociais, analisando o papel dessas redes no empreendedorismo de um imigrante. Os resultados ratificam estudos relatados na literatura, ou seja, as redes sociais representam fontes de vários tipos de recursos, entre eles capital financeiro, social e humano e ainda atuam como apoio emocional e de aconselhamento que, aliados, favorecem o empreendedorismo imigrante e étnico. A pesquisa também confirmou que as redes sociais são ferramentas valiosas para a criação e manutenção de novos negócios.

(C) 2018 Internext | ESPM. Todos os direitos reservados!

\section{INTRODUÇÃO}

As migrações internacionais têm crescido de forma expressiva em nível mundial, causando impactos de diferentes ordens em vários países no mundo, gerando tensões políticas e econômicas. Esse fenômeno migratório sempre foi um ato presente na sociedade e resulta em consequências econômicas e sociais para os países envolvidos (Martes, 2016). Recentemente, tem havido grande preocupação dos governos em discutir e pensar estratégias para acolher o grande contingente de imigrantes que, carregados de sonhos e esperança, deixam para trás suas histórias, famílias, bens, entre outros, para reiniciar a vida em país distante. "Se o grande fluxo de imigrantes pode causar transtornos para o país de destino, tais como problemas com a segurança nacional, (Silva, 2013), sobrecarga no sistema de saúde (Sasaki \& de Oliveira Assis, 2016) e transportes entre outros (de Castro Lima \& Castro, 2018), por outro lado, a literatura sobre o tema mostra que a migração internacional pode proporcionar crescimento econômico e desenvolvimento regional com a participação dos imigrantes não apenas no

\footnotetext{
${ }^{1}$ Contato do autor - Email: gislenecordeirodiniz@gmail.com
}

mercado de trabalho, mas também como empreendedores (Lima \& Castro, 2017).

De acordo com dados da pesquisa internacional realizada no período de 2010 a 2015 pelo Global Migration Data Analysis Centre (GMDAC) e pela International Organization for Migration (IOM), divulgados em 2017, cerca de 710 milhões de pessoas em todo o mundo expressam o desejo de migrar para algum país no exterior. O destino mais desejado são os Estados Unidos, e o Brasil aparece na lista dos 20 mais procurados pelos imigrantes (GMDAC, 2017). Independentemente do destino escolhido, pesquisas empíricas têm demonstrado que, ao se estabelecer em um novo país, o imigrante encontra um novo contexto social e econômico e fatores que o condicionam a buscar recursos que o ajudem a sobreviver no país de acolhimento (Halter, 2007; Lima \& Castro, 2017; Portes \& Zhou, 1992; Sanders \& Nee, 1996; Wilson \& Portes, 1980; Zhou, 2004). Dadas as inúmeras dificuldades de adaptação em país estrangeiro, muitos imigrantes encontram na informalidade seu sustento e buscam no empreendedorismo uma forma de gerar renda e se inserir econômica e socialmente. Com a 
indisponibilidade de recursos financeiros oriundos de instituições formais de crédito dado o seu status, muitas vezes, de irregular ou ilegal, parecem contar com o apoio de suas redes sociais para iniciar um negócio e promover o desenvolvimento de seu empreendimento.

Buscaram-se informações sobre o tema na literatura e foi constatada grande lacuna no campo de estudo do empreendedorismo imigrante nas literaturas nacionais e internacionais. Pesquisas recentes a partir de revisão bibliométrica no tema empreendedorismo imigrante e étnico (Cruz, Falcão \& Barreto, 2017) e Systematic review of immigrant entrepreneurship literature: previous findings and ways forward (Aliaga-Isla \& Rialp, 2013) corroboram essa afirmação e revelam a escassez de estudos sobre o tema especialmente no campo de estudo da administração. Diante da relevância do tema na atualidade, a escassez de estudo na área e seu ineditismo, faz-se necessário ampliar o estudo a respeito dele.

Considerando o exposto, estabeleceu-se como questão norteadora para este trabalho: como as redes sociais no país de acolhimento atuam no apoio aos negócios de um empreendedor imigrante sírio no Brasil?

O artigo foi estruturado da seguinte forma: após esta introdução, estabelece-se o referencial teórico que norteou a pesquisa e a análise dos dados coletados. No item 3, descreve-se a metodologia utilizada no trabalho de investigação. No item 4, apresenta-se o caso do imigrante empreendedor sírio e, no item 5, a análise da sua trajetória empreendedora e do papel da rede no processo. Por fim, apresentam-se as considerações finais do trabalho.

\section{REFERENCIAL TEÓRICO}

\section{Empreendedorismo Imigrante}

O empreendedor imigrante tem conquistado a atenção de diversos estudiosos como Light (1972), Portes (2003), Portes e Zhou (1992, 2012), Portes e Sensenbrenner (1993), Zhou (2004), Aldrich e Ward (1990), Sanders e Nee (1996, 1987), Martes e Rodrigues (2004), Marcovitch (2007), Halter (2007), Brzozowski, Cucculelli e Surdej (2014), Cruz, Falcão e Barreto (2017) e Nazareno, Zhou e You (2018), entre outros. Suas pesquisas documentam conceitos importantes para a diferenciação do tipo de negócio exercido pelo imigrante e em que âmbito ele ocorre.
Dessa maneira, para se discutir o empreendedorismo imigrante é importante reconhecer suas diferentes denominações e suas peculiaridades. De acordo com Halter (2007), ao chegar ao país de acolhimento, alguns imigrantes enfrentam uma série de barreiras como falta de proficiência na nova língua, baixo nível de escolaridade, falta de documentos com permissão para trabalhar no país, choques culturais e falta de aceitação e reconhecimento como pessoa pertencente àquela sociedade. Por vezes, esse cenário torna sua adaptação complexa, tornando os imigrantes menos competitivos no mercado de trabalho formal, o que acaba por estimular iniciativas empreendedoras como forma de superar as restrições econômicas e de sobrevivência dessa população (Halter, 2007; Zhou, 2004).

Nesse sentido, Peroni, Riilio \& Sarracino (2016) tentam explicar a relação entre imigração e o empreendedorismo. Conforme os autores, os imigrantes em situações de desvantagens linguísticas, raciais e educacionais são mais propensos a empreender. Outros estudos destacam o papel dos traços culturais herdados de seus países de origem como facilitadores da manifestação de iniciativas empreendedoras. A partir da teoria do capital humano, Sanders \& Nee (1996) e Arregle, Batjargal, Hitt, Webb, Miller \& Tsui (2015) apregoam que as redes sociais dos imigrantes exercem papel de facilitadoras de acessos a recursos como mão de obra, financeiros e de suporte emocional-familiar.

Zhou (2004) ressalta como determinantes para o empreendedorismo as condições ou contextos de saída do imigrante de seu país de origem. Na sua avaliação, em alguns casos, o imigrante leva consigo recursos como capital humano, motivação e até mesmo recursos financeiros, possuindo, assim, vantagem em relação aos demais imigrantes, que muitas vezes enfrentam as barreiras já mencionadas. Estudos seminais como o de Zhou (2004) analisam a questão do enclave étnico, definindo-o como o local onde membros de grupos e comunidades étnicas residem. A ideia central da perspectiva é que o imigrante aumenta sua chance de iniciar um novo negócio em áreas de enclave étnico, uma vez que é alto o nível de solidariedade e de valores culturais partilhados entre o grupo ou comunidade. A teoria do embeddedness ou enraizamento/imersão sugere que os imigrantes pertencentes a redes étnicas alavancam suas possibilidades de empreender, haja vista que os membros integrantes dessa rede podem fornecer aos imigrantes coétnicos diversos tipos de 
Empreendedorismo Imigrante e Étnico: O Papel das Redes Sociais no Processo Empreendedor de um Imigrante Sírio no Brasil

recursos como, por exemplo, capital financeiro e capital social (Granovetter, 2005).

Além das perspectivas que tentam explicar os motivos que levam o imigrante a empreender, é necessário definir quem são os atores envolvidos nesse processo. Zhou (2004), Halter (2007) e Cruz et al., (2017) conceituam empreendedores étnicos como aqueles que possuem negócio próprio e que estejam ligados de forma comum a uma herança cultural, compartilhando da mesma estrutura social, comportamental e das transações econômicas comuns ao grupo. Esclarecem sobre a diferença entre empreendedor imigrante e empreendedor étnico, sendo que a principal característica do empreendedor imigrante é que ele não se identifica com sua comunidade étnica, seja por diferenças nas práticas comerciais, comportamentais, por valores culturais divergentes ou até mesmo por não considerar seus compatriotas. Normalmente, faz a opção por tipos de negócios não relacionados à sua etnia e busca se dissociar e diferenciar de seu grupo étnico.

Zhou (2004) estabelece duas categorias de empreendedorismo étnico, sendo: minoria intermediária e empresários de enclave. A categoria denominada minoria intermediária é composta por grupos étnicos que realizam atividades econômicas e que são mediadores nas negociações entre a elite e as massas do enclave. Normalmente, estabelecem nichos de mercado étnicos em bairros cuja população é de baixa renda ou em guetos de imigrantes, a fim de atenderem às demandas dos coétnicos que comumente não são oferecidas pela economia tradicional. Já os empresários de enclaves diferenciam-se principalmente por seus negócios se autossustentarem pela população pertencente ao enclave étnico. Essas categorias de empreendedorismo apresentam novos conceitos, como o de economia étnica e o de economia de enclave. Ambos estão relacionados entre si. 0 conceito de economia étnica abrange empresas de minorias intermediárias, empresas de coétnicos localizadas em enclaves étnicos e empresas étnicas atuantes na economia em geral. A mobilidade entre as pessoas pertencentes a esses grupos cria oportunidades de empreendedorismo e empregos para seus coétnicos (Zhou, 2004). O conceito de economia de enclave apresentado por Wilson e Portes (1980), baseado no mercado de trabalho de cubanos na cidade de Miami, inclui quase todos os tipos de negócios, funcionando como um guardachuva étnico. Suas atividades econômicas incluem o comércio e a produção voltada para o mercado em geral e não apenas nichos evitados por nativos. A economia de enclave também é alimentada por solidariedade limitada e confiança. É limitada, pois se restringe apenas aos membros pertencentes ao grupo e inicialmente não tem relação apenas com questões de cunho financeiro - o que a estabelece é a situação comum de adversidade vivenciada. São celeiros de mão de obra barata e confiável, cuja disponibilidade desses recursos se torna um diferencial para os empresários imigrantes (Portes \& Sensenbrenner, 1993). Enfim, na literatura que discute empreendedorismo imigrante percebe-se a relevância do papel das redes sociais não apenas para facilitar e agilizar a adaptação do imigrante ao novo país, mas também como base de apoio para o estabelecimento de atividades empreendedoras. Elas são fontes de vários tipos de recursos, entre eles os capitais financeiro, social e humano, em que a solidariedade limitada e a confiança se tornam moedas de grande valia para o fortalecimento do espírito empreendedor imigrante (Zhou, 2004).

A Tabela 1 sintetiza as principais terminologias e definições para o empreendedorismo de imigrantes.

Tabela 1 - Principais terminologias encontradas no empreendedorismo de imigrantes

\begin{tabular}{clc}
\hline Termo & \multicolumn{1}{c}{ Características } & Principais Autores \\
\hline $\begin{array}{c}\text { Empreendedorismo } \\
\text { imigrante }\end{array}$ & $\begin{array}{l}\text { Normalmente faz a opção por tipos de negócios não } \\
\text { relacionados à sua etnia e busca se dissociar e } \\
\text { diferenciar de seu grupo étnico. }\end{array}$ & $\begin{array}{c}\text { Zhou, 2004; Cruz et al., 2017; } \\
\text { Nazareno et al., 2018 }\end{array}$ \\
\hline $\begin{array}{c}\text { Empreendedorismo } \\
\text { étnico }\end{array}$ & $\begin{array}{l}\text { Identifica-se e mantém relacionamento com } \\
\text { coétnicos, define estratégias de negócios voltadas } \\
\text { para público da mesma etnia voltado para o enclave. }\end{array}$ & $\begin{array}{c}\text { Zhou, 2004; Cruz et al., 2017; } \\
\text { Nazareno et al., 2018 }\end{array}$ \\
\hline \multirow{2}{*}{$\begin{array}{l}\text { Enclave étnico ser definido como o local onde membros de } \\
\text { grupos e comunidades étnicas residem. }\end{array}$} & \multicolumn{2}{c}{$\begin{array}{l}\text { Zhou, 2004; } \\
\text { Sanders e Nee, 1987; Nazareno et al., 2018 }\end{array}$}
\end{tabular}




\begin{tabular}{|c|c|c|}
\hline $\begin{array}{l}\text { Minoria étnica } \\
\text { intermediária }\end{array}$ & $\begin{array}{l}\text { Composta por grupos étnicos que realizam atividades } \\
\text { econômicas e são intermediários nas negociações } \\
\text { entre a elite e as massas do enclave. Atendem às } \\
\text { demandas dos coétnicos que não são oferecidas pela } \\
\text { economia tradicional. }\end{array}$ & $\begin{array}{c}\text { Zhou, 2004; Wilson e Portes, 1980; } \\
\text { Nazareno et al.,2018 }\end{array}$ \\
\hline Economia de enclave & $\begin{array}{l}\text { Inclui quase todos os tipos de negócios, funciona } \\
\text { como um guarda-chuva, suas atividades econômicas } \\
\text { incluem o comércio e a produção direcionada ao } \\
\text { mercado em geral, diversidade nos negócios e ampla } \\
\text { variedade de atividades econômicas e não apenas } \\
\text { nichos evitados por nativos. }\end{array}$ & $\begin{array}{l}\text { Wilson e Portes, 1980; } \\
\text { Zhou, 2004; Nazareno et al., } 2018\end{array}$ \\
\hline Economia étnica & $\begin{array}{l}\text { O conceito de economia étnica abrange empresas de } \\
\text { minorias intermediárias, empresas de coétnicos } \\
\text { localizadas em enclaves étnicos e empresas étnicas } \\
\text { atuantes na economia em geral. }\end{array}$ & $\begin{array}{c}\text { Wilson e Portes, 1980; } \\
\text { Zhou, 2004; Cruz et al. 2017; } \\
\text { Nazareno et al., } 2018\end{array}$ \\
\hline Solidariedade limitada & $\begin{array}{l}\text { A solidariedade limitada inicialmente não tem relação } \\
\text { com questões de cunho financeiro. Trata-se de } \\
\text { solidariedade emergida das adversidades comuns } \\
\text { enfrentadas pelos imigrantes. Pode criar normas de } \\
\text { apoio mútuo, princípios e comportamentos entre } \\
\text { aquela comunidade. }\end{array}$ & $\begin{array}{l}\text { Portes e Sensenbrenner 1993; } \\
\text { Zhou, 2004; Nazareno et al., } 2018\end{array}$ \\
\hline
\end{tabular}

Fonte: elaborado pelos autores.

\section{Redes sociais e Empreendedorismo Imigrante}

Pesquisas empíricas realizadas por diversos pesquisadores tais como Granovetter $(1973,2005)$, Martes e Rodrigues (2004), Zhou (2004), Sanders \& Nee (1996), Arregle et al. (2015), Mariz e Bógus (2013), Peroni et al. (2016), Corrêa e Vale (2017), Vale e Guimarães (2010), Vasconcelos, Rezende, Guimarães \& Fachin (2007), entre outros, têm demonstrado que as redes sociais são ferramentas importantes e essenciais para o desenvolvimento do empreendedorismo. Os laços existentes entre indivíduos constituem papel fundamental para o entendimento de como eles influenciam o empreendedorismo. Granovetter (1973) propõe duas definições quanto aos tipos de laços, denominandoos como laços fortes e laços fracos. São consideradas laços fortes as relações mantidas entre indivíduos em que é possível verificar identidade comum. Assim, os laços fortes são encontrados entre pessoas próximas, do mesmo círculo social, entre parentes, familiares e amigos, ou seja, quanto maior a interação e similaridade entre os atores, maior a força do laço. Ainda, considera laços fracos aqueles mantidos entre indivíduos que são colegas ou conhecidos.

Corrêa e Vale (2017) explicitam que por mais que os laços fortes proporcionem mais acessibilidade a recursos, eles não são capazes de fornecer a sustentação necessária ao empreendedorismo dos indivíduos interligados à rede. Nesse âmbito,
Granovetter (1973) percebe a força dos laços fracos, pois esse tipo de laço gera redes que proporcionam vantagens para seus membros, exercendo papel de pontes, transpondo distâncias e ampliando o universo de possibilidades. As redes que interagem com mais intensidade e maior frequência são consideradas eficazes e densas, formando grupos mais coesos e são mais percebidas em grupos que convivem em cenário similar, como etnias, grupos com viés ideológico forte ou com aspectos profissionais comuns. As redes que interagem em menor grau (laços fracos) são denominadas redes estendidas e são menos densas (Granovetter, 1973), podendo gerar mais benefícios, haja vista que a probabilidade de acesso a oportunidades e informações não redundantes é maior se comparada às redes densas. Corrêa e Vale (2017) complementam que a dinâmica entre laços fortes e laços fracos são fundamentais para a atividade empreendedora.

Ao discutir a relação imbricada entre atividade econômica e redes sociais - embeddedness -, Granovetter (2005) mostra que as relações econômicas estão imersas nas relações sociais e viceversa. Acrescenta que a partir dessas interações é muito comum nascerem laços de amizade e de confiança entre os atores, produzindo ganhos inicialmente não previstos. Para o empreendedorismo, esse conceito de embeddedness (imersão) é importante, pois empreendedores 
Empreendedorismo Imigrante e Étnico: O Papel das Redes Sociais no Processo Empreendedor de um Imigrante Sírio no Brasil

podem estar imersos em diversos tipos de redes formadas pelas relações sociais e econômicas (Hite, 2003, 2005). Para a autora, os indivíduos podem estabelecer laços inicialmente apenas com a intenção de se relacionar no âmbito pessoal, porém esses relacionamentos podem evoluir para relações de caráter econômico, da mesma forma que os laços gerados por relações econômicas podem alargar o nível de confiança, gerando laços de amizades longevos.

Um conceito mais abrangente, o de capital social, é sugerido por Coleman (1988). O autor define o capital social como recursos oriundos das estruturas sociais dos atores, que podem ser utilizados para a realização de interesses e objetivos próprios e destaca três formas de capital: físico, humano e social. O capital físico é compreendido como elementos ligados à produção tais como ferramentas, máquinas e outros equipamentos. O capital humano diz respeito às habilidades e competências dos indivíduos. E capital social é aquele gerado a partir das mudanças e conexões das estruturas sociais de cada indivíduo. Portes e Sensenbrenner (1993), Portes e Zhou (1992), Granovetter (2005) e Zhou (2004) fazem menção ao capital social decorrente de reciprocidade e da solidariedade limitada. Esse tipo de capital surge entre indivíduos independentemente de valores financeiros. Eles estão pautados na solidariedade e nas normas criadas entre o grupo. A confiança é a base do relacionamento e pode gerar benefícios $e$ proporcionar crescimento empresarial. Outra fonte de recursos importante para o empreendedorismo são os oriundos dos laços familiares. Eles podem oferecer diversos tipos de recursos em apoio ao empreendedor na superação dos desafios inerentes ao crescimento empresarial (Arregle et al., 2015; Portes \& Zhou, 1992; Sanders \& Nee, 1996).

Arregle et al. (2015) ressaltam que os laços de rede de empreendedores podem ser úteis de três maneiras: como rede de conselho, rede de recursos e rede de apoio emocional, sendo que cada tipo afeta de forma diferente o desenvolvimento dos negócios. As redes de conselho são valiosas para auxiliar o empreendedor a solucionar problemas que the causam incerteza, ajudando no reconhecimento de oportunidades de novos produtos ou serviços, em desenvolvimento de tecnologias e até mesmo em informações sobre alterações de leis e regulamentos. Elas facilitam o acesso ao conhecimento de mercado e às decisões de cunho financeiro (Arregle et al., 2015). Já as redes de apoio emocional proporcionam amparo psíquico e emocional, ajudando o empreendedor na superação dos dilemas inerentes à atividade empreendedora e facilitando sua concentração na consolidação e crescimento dos negócios (Arregle et al., 2015). E as denominadas redes de recursos são fontes de apoio a diversos tipos de recursos como capital financeiro, mão de obra, matéria-prima, tecnologias, entre outros. Essa diversidade de recursos disponibilizada pelas relações interpessoais e organizacionais permite o desenvolvimento de competências empreendedoras e o crescimento empresarial (Arregle et al., 2015). Enfim, a literatura tem demonstrado, por meio das pesquisas empíricas, que as redes sociais são importantes no apoio ao empreendedorismo e que podem proporcionar crescimento e gerar vantagens competitivas aos negócios.

A Tabela 2 apresenta os recursos disponibilizados pelas redes sociais aos empreendedores.

Tabela 2- Recursos disponibilizados pelas redes sociais

\begin{tabular}{llll}
\hline \multicolumn{1}{c}{ Recursos } & \multicolumn{1}{c}{ Tipo } & \multicolumn{1}{c}{ Fonte } & Principais Autores \\
\hline \multirow{2}{*}{ Capital social } & & - Laços fracos & Coleman, 1988, Portes e Sensenbrenner, \\
& - Reciprocidade e & - Laços fortes & 1993, Portes e Zhou, 1992, Granovetter, \\
& solidariedade limitada & - Laços familiares & $(1973,2005)$ Zhou (2004) \\
\hline \multirow{2}{*}{ Capital físico } & - Ferramentas, máquinas & - Laços fracos & \\
& - Equipamentos & - Laços fortes & Coleman, 1988 \\
\hline Capital & - Habilidades e competências & - Laços familiares & \\
humano & dos indivíduos, mão de obra & - Laços fracos & Coleman, 1988 fortes \\
& de baixo custo & Sanders e Nee, 1996 \\
\hline & - Solução de problemas, & & \\
& - Reconhecimento de oportunidades de & & \\
& novos & - Laços fracos & \\
\hline
\end{tabular}


G. C. S. Diniz, L. O. Guimarães \& D. M. Fernandes

\begin{tabular}{|c|c|c|c|}
\hline $\begin{array}{l}\text { Rede de } \\
\text { conselhos }\end{array}$ & $\begin{array}{l}\text { serviços, novos produtos } \\
\text { - Desenvolvimento de novas tecnologias } \\
\text { informações legais, acesso a recursos } \\
\text { financeiros }\end{array}$ & $\begin{array}{l}\text { - Laços fortes } \\
\text { - Laços familiares }\end{array}$ & Arregle et al., 2015 \\
\hline $\begin{array}{l}\text { Rede de } \\
\text { recursos }\end{array}$ & $\begin{array}{l}\text { - Capital financeiro, } \\
\text { - mão de obra, - matéria-prima, } \\
\text { tecnologias }\end{array}$ & $\begin{array}{l}\text { - Laços fracos } \\
\text { - Laços fortes } \\
\text { - Laços familiares }\end{array}$ & Arregle et al., 2015 \\
\hline $\begin{array}{l}\text { Rede de apoio } \\
\text { emocional }\end{array}$ & $\begin{array}{l}\text { - Recursos psíquicos e emocionais } \\
\text { ajudando o empreendedor a focar } \\
\text { no crescimento dos negócios }\end{array}$ & $\begin{array}{l}\text { - Laços fracos } \\
\text { - Laços fortes } \\
\text { - Laços familiares }\end{array}$ & Arregle et al., 2015 \\
\hline
\end{tabular}

Fonte: elaborado pelos autores.

\section{Modelo Teórico para Análise dos Dados}

A discussão sobre o empreendedorismo imigrante, bem como sobre o papel das redes sociais de apoio ao processo empreendedor, permitiu elaborar um modelo teórico para subsidiar a análise dos dados, conforme se segue.

\section{Processo Empreendedor Imigrante}

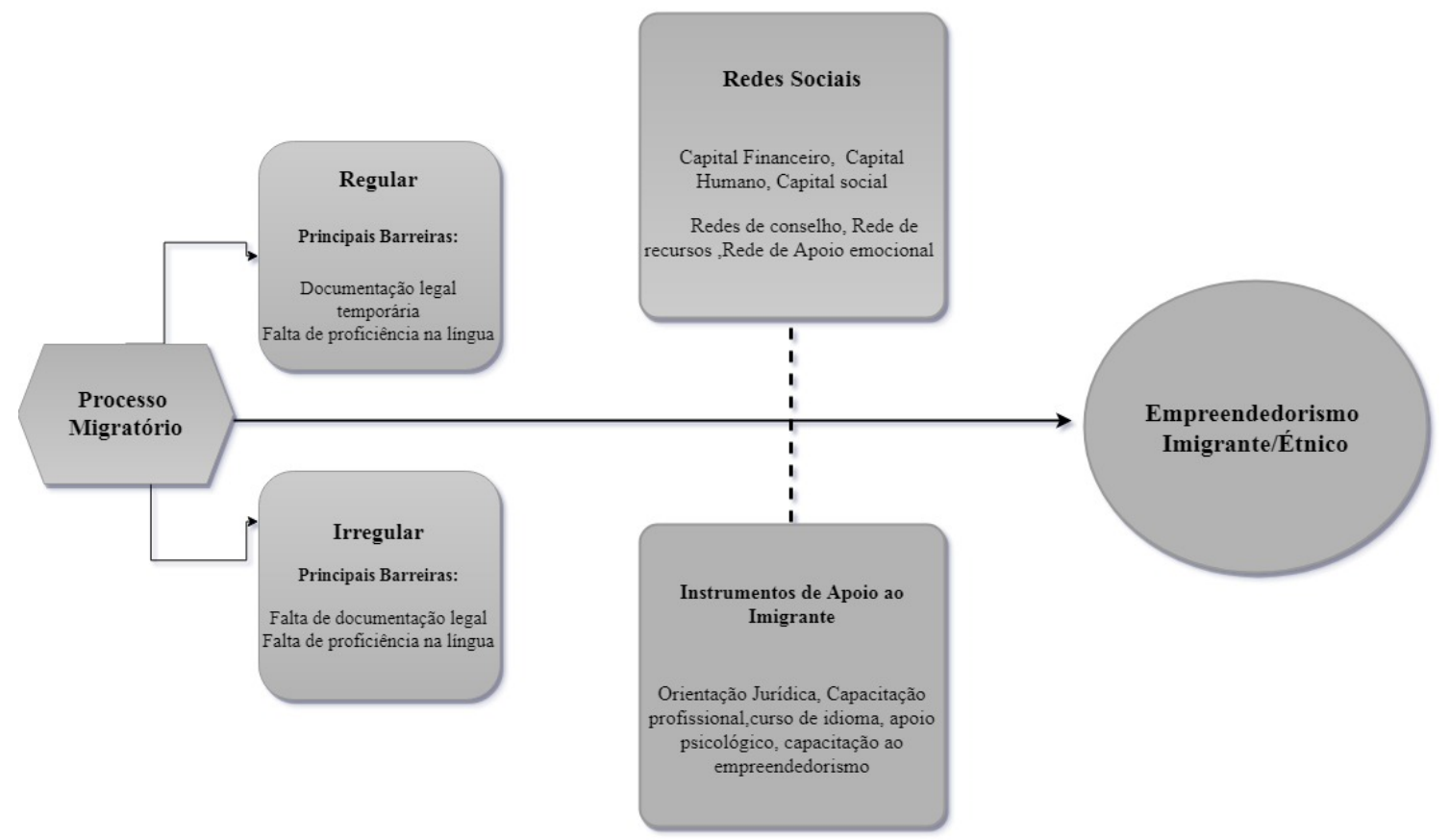

Figura 1 - Processo empreendedor imigrante Fonte: elaborado pelos autores.

O modelo da Figura 1 busca representar os elementos essenciais que compõem o processo empreendedor imigrante. De acordo com Zhou (2004), no processo migratório os contextos de saída são relevantes, dado que as condições em que o imigrante deixou seu país de origem - se voluntária ou involuntariamente, regular ou irregularmente podem afetar o ambiente, as condições e as oportunidades no país de destino, independentemente do nível de capital humano, estrutural e cultural do indivíduo.
Zhou (2004), Portes e Sensenbrenner (1993) e Wilson e Portes (1980) encontraram resultados semelhantes em suas pesquisas empíricas, em que apuraram que a falta de proficiência na língua, falta de documentação, falta de escolaridade, entre outros, são barreiras que dificultam ao imigrante estabelecer-se no mercado formal de trabalho. Diante dessas dificuldades, muitos imigrantes tornam-se empreendedores, buscando sustento, geração de renda e inserção econômica e social no país de acolhimento. Com a indisponibilidade de 
Empreendedorismo Imigrante e Étnico: O Papel das Redes Sociais no Processo Empreendedor de um Imigrante Sírio no Brasil

recursos financeiros oriundos de instituições formais de crédito dado ao seu status de irregulares ou à ausência de garantias para obtenção de empréstimos, os imigrantes parecem contar com o apoio de suas redes sociais para iniciar um negócio e promover o desenvolvimento de seu empreendimento (Granovetter, 1973, Halter, 2007; Portes \& Sensenbrenner, 1993; Zhou, 2004).

No modelo apresentado, em consonância com a literatura, consideram-se as redes sociais em uma linha tracejada como possível fonte de recursos de diversos tipos de capitais e diferentes formas de redes. Granovetter (2005) relata que a sobrevivência desses negócios é possível, haja vista que os empresários estão inseridos em redes sociais em que os laços formados a partir dos contatos com as díades fornecem aos empreendedores uma série de informações e recursos tais como financeiros, humano, social, entre outros. Autores como Granovetter (1973, 2005), Coleman (1988), Portes e Sensenbrenner (1993), Portes e Zhou (1992) e Arregle et al. (2015) reconhecem que a maioria dos empreendedores busca recursos financeiros por meio das redes sociais, sendo os laços fortes a principal fonte, especialmente os familiares. Hite $(2003,2005)$ e Granovetter $(1973,2005)$ acreditam que a relação mantida entre os laços fortes e fracos são forças propulsoras de um processo de alavancagem social capaz de promover as relações econômicas de sucesso e as relações pessoais.

Outro aspecto importante abordado por Aldrich e Waldinger (1990) são que as estruturas de oportunidade oferecidas pelas redes sociais de coétnicos favorecem o empreendedorismo voltado para o mercado étnico. Os membros da rede social mobilizam acesso a recursos, facilitam a organização do negócio, auxiliam nas estratégias de gestão e ajudam na adaptação do novo ambiente. Essas situações proporcionam o que Portes e Zhou (1992) e Zhou (2004) chamaram de solidariedade limitada, favorecendo o acesso a recursos e criando normas de relacionamentos e comportamentos entre os membros da rede que estejam passando por situações adversas no país de acolhimento. Entretanto, Zhou (2004) e Cruz et al. (2017) também identificam o perfil do empreendedor imigrante voltado para o mercado em geral. Esse empreendedor tem características distintas do empreendedor étnico. Sua principal diferença é o mercado de atuação e a relação mantida entre os coétnicos. Para os autores, os empreendedores que fazem a opção pela economia tradicional contam com o apoio de suas redes sociais para alavancagem de seu negócio, porém não são voltados para o enclave étnico e buscam se dissociar de seus coétnicos.

Ao estabelecer seu empreendimento no mercado, o imigrante parece ter grandes chances de expansão e de sucesso em sua atividade empreendedora. Nesse aspecto, percebe-se que o status do imigrante no país de acolhimento é de grande relevância, pois caso esteja irregular enfrentará fortes barreiras para a formalização e expansão de seus negócios. Enfim, a literatura revela que o processo empreendedor de imigrantes sofre diversas influências, perpassando desde seu contexto de saída até a escolha do tipo de negócio, bem como as possibilidades de expansão e formalização do empreendimento.

\section{ASPECTOS METODOLÓGICOS}

O presente trabalho é de natureza qualitativa, uma vez que a investigação de natureza qualitativa trabalha com valores, crenças, hábitos, atitudes, representações, opiniões e permite o aprofundamento nos fatos e processos dos indivíduos e dos grupos. Assim, favorece a compreensão da complexidade envolvida nos fenômenos, sempre preservando a fidedignidade e a validade dos resultados obtidos (Paulilo, 1999). O método utilizado foi a história de vida. De acordo com Miranda, Cappelle e Mafra (2014), esse método tem sido importante nas pesquisas realizadas no campo da Administração e nas pesquisas qualitativas, pois possibilita compreender as particularidades dos objetos/sujeitos de pesquisa no âmbito individual ou coletivo. Bosi (2003) e Lopes (2013) enfatizam que o método "história de vida" visa à compreensão do universo do qual os sujeitos fazem parte. A origem da utilização do método "história de vida" encontra-se nos trabalhos de Thomas \& Znaniecki (1927), que tiveram como objeto de estudo a organização, desorganização e reorganização de poloneses imigrantes nos Estados Unidos. Com base nos relatos coletados e nas análises de documentos como cartas, os autores puderam compreender e interpretar a trajetória vivida pelos imigrantes, revelando a importância das mudanças sociais para eles. Pesquisas empíricas nacionais pioneiras na utilização do método "história de vida" no campo da Administração, seja como método ou como técnica de coleta de dados (Cavedon \& Ferraz, 2005; Closs \& Antonello, 2011), sugeriram a contribuição do 
método de história de vida nos avanços dos estudos organizacionais, entre os quais interculturalidade, processos e aprendizagem gerencial e administração mercadológica, e nos reflexos das representações sociais no desenvolvimento de estratégias. Miranda et al. (2014) afirmam que, mesmo de forma tímida, o método tem crescido no campo da Administração.

O método "história de vida" busca construir conhecimento de maneira a dar voz ao sujeito por meio de seu relato, ou seja, contando sua história. Por meio das entrevistas em profundidade e do diálogo entre o sujeito e o entrevistador, pode-se verificar o modo como o sujeito vive e como ele afeta e é afetado pela sociedade (Lopes, 2013). Nesse sentido, Barros e Lopes (2014) argumentam que o método "história de vida" é essencialmente abundante nos estudos relacionados a fenômenos ligados a movimentos e mudanças sociais, fenômenos de migração, de mobilidade social, de marginalização e de exclusão, consequências de crises econômicas e sociais, bem como a trajetórias de trabalho e a mudanças profissionais. Enfim, considerando o objetivo deste trabalho, que busca analisar como as redes sociais no país de acolhimento atuam no apoio aos negócios de um empreendedor imigrante sírio no Brasil, o método "história de vida" fornece a possibilidade de estabelecer conexões entre os pesquisados e seus âmbitos sociais e profissionais. Por meio das narrativas do imigrante é possível fazer o recorte de suas vivências e experiências na jornada do empreendedorismo. É por essas razões que se acredita ser a história de vida o método mais adequado para o entendimento do fenômeno da imigração no seu campo de vida real.

\section{Coleta de Dados}

Este trabalho faz parte de uma pesquisa ainda em desenvolvimento. Já foram ouvidos três imigrantes empreendedores e suas redes sociais no Brasil e estão sendo ouvidos imigrantes empreendedores brasileiros nos Estados Unidos, com o objetivo de comparação. Entretanto, neste artigo está apresentado o relato de apenas um empreendedor imigrante. Os depoimentos revelam fatos e experiências vividas por ele na sua trajetória de vida até se tornar um empreendedor no Brasil. Com a finalidade de complementar, enriquecer e dar validade à pesquisa, foram realizadas entrevistas com as redes de convívio do entrevistado de maneira a confrontar os relatos e acrescentar informações, fatos e documentos fornecidos por pessoas próximas. De acordo com Miranda et al. (2014), na adoção do método "história de vida" não há números fixos de entrevistas, pois a partir dos acontecimentos marcantes mencionados nos depoimentos e dos nomes citados poderá surgir a necessidade de investigação de novos elementos e a inclusão de novos entrevistados.

Foram realizadas entrevistas em profundidade, observação não participante no empreendimento do entrevistado e levantamento documental. De acordo com Paulilo (1999), as entrevistas realizadas no método "história de vida" são denominadas entrevistas prolongadas, nas quais a interação entre o entrevistador e entrevistado se dá de forma contínua, podendo ser estabelecida como um encontro social, favorecendo a empatia, as percepções, os sentimentos e as emoções que propiciaram a narrativa do entrevistado. As entrevistas em profundidade permitem mapear e compreender o mundo da vida dos respondentes (Bauer \& Gaskell, 2017), sendo uma das mais importantes fontes de informações na pesquisa qualitativa, incluindo o estudo de caso individual como história de vida (Yin, 2005). Não foi elaborado roteiro prévio para entrevistas, pois de acordo com Miranda et al. (2014), na operacionalização das entrevistas na história de vida não é adequada a estruturação de questões, pois deve-se deixar o entrevistado à vontade para relatar sua história da maneira como lhe convier. O pesquisador deverá utilizar apenas a pergunta norteadora "conte-me a sua história" e deixar que o entrevistado comece por onde achar mais adequado. No entanto, antes de cada entrevista, foi realizada a escuta sistemática da entrevista anterior e sua transcrição, com a finalidade de nortear a próxima.

Para este trabalho foram realizadas seis entrevistas: três com o imigrante sírio, totalizando três horas de depoimento, e três com pessoas de sua rede - um irmão, um pastor e o empresário brasileiro que o apoiou.

As entrevistas com esses membros da rede do imigrante totalizaram duas horas e 40 minutos. Após a realização das entrevistas, foi feita a sua transcrição e, posteriormente, a leitura sistemática a fim de levantar fatos e falas que revelassem elementos importantes e que contribuíram para que o imigrante se tornasse um empreendedor, bem como os recursos oferecidos pelas redes sociais nesse processo. 
Empreendedorismo Imigrante e Étnico: O Papel das Redes Sociais no Processo Empreendedor de um Imigrante Sírio no Brasil

\section{DESCRIÇÃO DO CASO: A HISTÓRIA DE FOAD}

Foad é um refugiado de guerra no Brasil, tem 36 anos, casado e pai de três filhos, natural da cidade de Aleppo/Síria. Faz parte de uma família com pais e nove irmãos. Em virtude da guerra, seus irmãos estão espalhados pelo Brasil, Alemanha, Síria, Jordânia e Turquia. Até a data deste relato, seus pais estavam escondidos em um buraco em Aleppo, com água e comida restritas. Relata que quando morava na Síria trabalhava como chefe de cozinha em um grande restaurante. Tinha boas condições de vida e financeira, possuía duas casas, carros e sua esposa não precisava trabalhar. A guerra trouxe muita destruição e o entrevistado e toda a sua família perderam tudo o que tinham e não havia como sobreviver, então foram tentar a vida na Jordânia.

[...] Quando começou a guerra, a última cidade a ser atacada foi Aleppo, mas foi a pior cidade também [tosse, emoção]. A guerra então foi dificil, porque com guerra não tem trabalho, e se não trabalhar é difícil para gente viver, não tem alimento. Não pagava aluguel, mas temos que viver, tem alimento que precisa ser comprado, tem as crianças. Então como não havia trabalho, eu saí da Síria, e consegui ir para Jordânia e fiquei lá um ano e três meses. (Foad)

Ao chegar à Jordânia, ainda enfrentou muitas barreiras, pois na Jordânia, os sírios não têm autorização para trabalhar. Conta que passou fome e foi ajudado por uma igreja cristã local. Juntamente com essa igreja, havia uma ONG brasileira chamada Missão em Apoio à Igreja Sofredora (MAIS), que ajudou Foad e sua família a virem para o Brasil. Ao chegar ao Brasil, foi para a cidade de Betim, por intermédio da ONG, da igreja Batista da Lagoinha e de uma advogada chamada Renata. A ONG o ajudou a solicitar o refúgio e a tirar os documentos legais aqui no Brasil. A igreja em Betim, Minas Gerais, ofereceu abrigo e custeou suas despesas por seis meses. Após esse período, conseguiu trabalho na igreja com serviços gerais. Foad diz que, por não falar português, teve dificuldade em conseguir trabalho e vendia quibe na igreja.

[...] a igreja arcou com todas as despesas por seis meses, depois de seis meses eles pagaram só o aluguel e parou de pagar água e luz. Eu sofri muito, foi muito sofrido porque teve a questão da língua, pois, para arrumar um emprego melhor precisava falar a língua e não tinha quem nos ensinasse, foi muito difícil. O trabalho que arrumei pagava um salário mínimo, ou seja, novecentos reais, mas você recebe menos que isto porque tem os descontos, e isto aqui no Brasil não dá para fazer quase nada. E eu tenho três filhos e como vão viver com isto? Eu faço quibe para vender na igreja, ganho pouco. (Foad)

Foad relata que esse período foi difícil e que passou fome com sua família aqui no Brasil também. A advogada Renata ficou sabendo que ele estava passando por dificuldades e resolveu ajudar. Renata fez contato com seus amigos por meio de redes sociais na internet e contou a situação de Foad. Muitas pessoas ajudaram, entre elas a família de Sr. Lorvandir, pessoa de grande influência em Betim, e atualmente muito importante na vida do entrevistado. Ana Paula, filha do Sr. Lorvandir, disponibilizou-se a dar aulas de Português para os imigrantes e promoveu um jantar no qual Foad foi o cozinheiro. A intenção era apresentá-lo, bem como seus dotes culinários, para a alta sociedade de Betim. A partir desse jantar Foad começou a cozinhar em festas e eventos pela cidade. Na ocasião, conheceu uma jornalista de um jornal de grande circulação na cidade, que se prontificou também a ajudá-lo. Escreveu sua história no jornal e criou uma página no Facebook para divulgação de seu trabalho.

[...] Aconteceu que a filha dele fez um jantar, eles já haviam ido até a nossa casa e gostaram muito da minha comida. Ela disse: eu vou fazer um jantar e convidar pessoas bem de vida para conhecerem sua comida. Daí comecei a fazer festas para eles. Ela fez uma festa e chamou pessoas bem ricas daqui. Na ocasião estava uma jornalista, o nome dela é Joelma e ela é daqui de Betim, tem um escritório aqui. Ela me disse: "olha, eu também vou te ajudar, vou fazer uma página para você, eu tenho muitos amigos no Facebook, eu vou divulgar seu trabalho, também vou te ajudar".(Foad)

Entre todas as manifestações de ajuda e de apoio recebidas, Foad disse que não poderia deixar de relatar que o Sr. Lorvandir é muito importante para ele e sua família. Disse que a ajuda oferecida por ele não foi financeira, mas de cunho emocional, e o considera um pai brasileiro. Sr. Lorvandir comentou que, certo dia, ofereceu um jantar em sua casa para Foad e seu irmão recém-chegado da Síria, chamado Farahd. Nesse jantar, Foad e sua esposa Yasmin pediram ao Sr. Lorvandir que ele e sua esposa fossem seus pais aqui no Brasil.

[...] Nós fizemos um jantar para o Foad e para o Farahd, irmão dele que trabalha comigo lá na empresa. Durante a conversa, a Yasmim e o Foad pediram que a gente fossem pais deles aqui no 


\section{G. C. S. Diniz, L. O. Guimarães \& D. M. Fernandes}

Brasil. E aquilo foi uma emoção muito grande, $e$ aceitamos ser pais deles aqui no Brasil. E esse negócio de ser pai passou a ser pai mesmo, assim, viver todos os problemas que tem aqui. (Lorvandir)

Logo depois, uma sobrinha do Sr. Lorvandir sugeriu ao seu esposo, empresário na cidade, que abrisse um restaurante com Foad. O entrevistado relata que a princípio ficou receoso, pois não tinha recursos financeiros para montar um restaurante. Seu atual sócio, porém, disse que entraria com os recursos financeiros e que ele entraria com o trabalho.

Foad aceitou a proposta e hoje o restaurante tem duas lojas em funcionamento. Sr. Lorvandir esclarece que ajudou Foad e sua família por perceber que seus próprios problemas são muito menores do que o que muitas pessoas que vivem neste mundo, como, por exemplo, pessoas em situações semelhantes à vivenciada por Foad. Os depoentes mencionaram um outro sírio que também recebeu apoio da Igreja e de sr. Lorvandir.

[...] Tem outro sírio que também estava com a gente. Ele é solteiro e também estava na Igreja da Lagoinha. Acho que a Igreja cuidou dele por uns dois anos. Depois ele também estava sofrendo $e$ não tinha trabalho direito, o pastor da lgreja disse: "tem um sírio aqui que está sofrendo e como ele não fala bem o português precisamos que você traduza para nós, para saber o que ele está sentindo e por que ele está sofrendo" Então eu fui até lá para ver e quando cheguei vi que ele estava sofrendo. Então falei com meu pai brasileiro e ele foi trabalhar com ele. Meu pai brasileiro abriu uma pequena empresa de marcenaria com ele para ele trabalhar e ele está trabalhando lá. (Foad)

\section{ANÁLISE DO CASO}

Verifica-se, nos relatos dos depoentes, que de acordo com o mencionado na literatura por Zhou (2004), Portes e Sensenbrenner (1993) e Wilson \& Portes (1980), bem como o apresentado pelo modelo teórico de análise dos dados, a falta de proficiência na língua e os contextos de saída do imigrante do país de origem afetam diretamente as oportunidades no país de destino, o que acabou levando Foad a se tornar um empreendedor com o objetivo de gerar recursos financeiros para sua subsistência e a de sua família. Outro aspecto verificado pelas declarações é o importante papel desempenhado pelas díades formadas a partir das relações sociais. Eles são fontes de recursos financeiros, de recursos sociais e até mesmo de recursos emocionais, como mencionado por Granovetter (1973, 2005) e Arregle et al. (2015). A partir dos depoimentos, verifica-se que as redes formadas a partir dos laços fracos, como identificado por Granovetter (2005), proporcionaram acesso a recursos financeiros e a apoio emocional, favorecendo e promovendo o empreendedorismo.

[...] Então, eu preciso mencionar uma família, eles são como meu pai e minha mãe brasileiros, mas pai e mãe de verdade! Ele chama Lorvandir. Eles são pessoas muito boas. Elas para mim são melhores que mil igrejas. Tem que falar mesmo, ele nos deu carinho, acolhimento... ele não me ajudou com dinheiro, mas, ele ajudou com muita coisa. Agora eu falo assim com meu filho: "o Lorvandir chegou..." e ele já vai correndo para encontrá-lo lá fora. Porque ele dá muito amor e carinho, muito, muito. (Foad)

[...] então a sobrinha do Lorvandir conhecia meu atual sócio. Ela falou para ele: "Por que você não tenta abrir uma restaurante, você vai ganhar bem com o Foad. Ele tem um posto de gasolina, o meu sócio é dono de um posto também." Então ele me chamou para conversamos e disse para abrirmos o restaurante...(Foad)

Percebemos a relação imbricada entre atividade econômica e redes sociais - embeddedness evidenciando que as relações econômicas estão imersas nas relações sociais e vice-versa e que estas estão incorporadas nas redes, na cultura, na política e na religião. Constatamos que os laços de amizade e de confiança entre os atores evoluíram para laços econômicos, produzindo vantagens de diferentes ordens (Granovetter, 2005). Verificamos o relevante papel dos laços fracos, bem como o alcance das denominadas redes estendidas gerando benefícios e acessos a oportunidades, como evidenciado abaixo:

[...] Um dia o Foad me ligou e disse: Lorvandir, eu estou precisando de sua ajuda. Eu falei: "o que foi, Foad?" "Tem um rapaz amigo nosso que veio da Síria, ele é marceneiro, arruma alguma coisa para ele, por favor." Eu falei: "Foad, mais tarde eu vou passar aí na sua casa para conversar com ele, o nome dele é Toni." Fui conversar com o Toni, eu vi ele mexendo e disse: "ô Toni, me dá uns dez a quinze dias para eu pensar em alguma coisa." Eu pensei, pensei, emprego não está tendo neste país, não tem emprego. Aí eu perguntei para ele: "quanto que custaria para montar uma marcenaria?" Ele falou: "Sr. Lorvandir, para começar custa tanto." Aí eu perguntei: "você quer montar alguma coisa? Vamos montar." Ai eu montei para ele e meu filho." (Lorvandir) 
Empreendedorismo Imigrante e Étnico: O Papel das Redes Sociais no Processo Empreendedor de um Imigrante Sírio no Brasil

Entre as redes estendidas, identificamos o grande valor das redes sociais atuando como rede de conselho, rede de apoio emocional e rede de recursos na criação e manutenção de novos negócios, auxiliando o empreendedor na solução de problemas como fonte de recursos financeiros, desenvolvimento de competências empreendedoras e facilitando o crescimento e consolidação dos negócios (Arregle et al., 2015).

Além das constatações em relação ao papel das redes, foi possível notar nos depoimentos o que Aldrich e Waldinger (1990) afirmam: que diversas vezes imigrantes buscam oportunidades de negócios voltadas para o mercado étnico, ligadas à sua herança cultural, gerando o empreendedorismo étnico. Apurou-se também o empreendedorismo imigrante na atividade de marcenaria exercida por Toni, membro da rede social de Foad. De acordo com Zhou (2004) e Cruz et al. (2017), o empreendedorismo imigrante faz a opção por tipos de negócios não relacionados à sua etnia. Mesmo não pertencendo a um enclave étnico, foi possível verificar Foad exercendo o papel de minoria intermediária no apoio ao empreendedorismo imigrante de Toni, seu cóetnico.

Detectaram-se os empreendedorismos étnico e imigrante inseridos no contexto de economia de enclave e economia étnica, conforme sugerido por Wilson e Portes (1980) e Zhou (2004), em que é possível verificar tipos de negócios distintos funcionando como um guarda-chuva, incluindo negócios voltados para o mercado étnico bem como para o mercado atuante na economia em geral. Verificamos o aproveitamento do capital humano nas atividades exercidas por ambos os imigrantes, que empreenderam em atividades semelhantes às exercidas na Síria ratificando a teoria do capital humano mencionada por Sanders \& Nee, (1996) e Arregle et al.(2015).

\section{Considerações Finais}

Este trabalho buscou analisar como as redes sociais no país de acolhimento atuam no apoio dos negócios dos empreendedores imigrantes sírios no Brasil. Por meio dos relatos, buscou-se conhecer a história pessoal do entrevistado e entender como ocorreu o processo empreendedor e identificar os tipos de recursos disponibilizados pelas redes sociais na criação e na manutenção de novos negócios. Por meio dessa rica história, foi possível perceber a relevância do papel das redes sociais não apenas para facilitar e agilizar a adaptação do imigrante ao novo país, mas também como base de apoio para o estabelecimento de atividades empreendedoras. Os resultados reforçam estudos anteriores, nos quais as redes sociais representam fontes de vários tipos de recursos, entre eles capital financeiro, social e humano e como rede de apoio emocional ajudando, assim, a fortalecer as ações empreendedoras de imigrantes (Zhou, 2004). A pesquisa também evidenciou que as redes sociais são ferramentas valiosas para a criação e manutenção de novos negócios (Granovetter, 1973, 2005; Portes \& Sensenbrenner 1993; Sanders \& Nee, 1996; Zhou, 2004, Vale \& Guimarães, 2010). Para esses autores, as atividades econômicas e sociais exercidas com o apoio de redes sociais geram vantagens competitivas e acesso a diversos tipos de recursos que são importantes para a alavancagem ou manutenção do empreendimento.

Durante a análise dos dados, percebeu-se o ganho metodológico obtido pela adoção do método "história de vida", que nos permitiu aprofundar e identificar os recursos disponibilizados pela rede no processo empreendedor. Adicionalmente, acreditase que os resultados contribuem para diminuir a escassez de estudos sobre empreendedorismo imigrante e étnico sob as lentes da Administração. Há de se ressaltar a limitação deste estudo por se tratar de história de vida única, não nos possibilitando comparar os resultados. Entretanto, por meio da validação de dados usando diferentes fontes de informações, foi possível estabelecer uma cadeia de evidência, respaldando os resultados obtidos com resultados semelhantes encontrados em outras pesquisas empíricas.

Os resultados deste trabalho poderão ser utilizados para aprofundar a compreensão do papel das redes sociais no processo empreendedor, bem como as abordagens do empreendedorismo imigrante e étnico. Sugere-se, para estudos futuros, a exploração das ramificações do tema, como o empreendedorismo transnacional, não explorado neste trabalho. 


\section{REFERÊNCIAS}

Aldrich, H. E., \& Waldinger, R. (1990). Ethnicity and entrepreneurship. Annual Review of Sociology, 16(1), 111-135.

Aliaga-Isla, R., \& Rialp, A. (2013). Systematic review of immigrant entrepreneurship literature: previous findings and ways forward. Entrepreneurship \& Regional Development, 25(9-10), 819-844

Arregle, J. L., Batjargal, B., Hitt, M. A., Webb, J. W., Miller, T., \& Tsui, A. S. (2015). Family ties in entrepreneurs' social networks and new venture growth. Entrepreneurship Theory and Practice, 39(2), 313-344.

Barros, V. A., \& Lopes, F. T. (2014). Considerações sobre a pesquisa em história de vida. In: E. M. Souza (org.). Metodologias e analíticas qualitativas em pesquisa organizacional: uma abordagem teórica conceitual. Vitória: EDUFES. (296 p).

Bauer, M. W., \& Gaskell, G. (2017). Pesquisa qualitativa com texto, imagem e som: um manual prático. Petrópolis: Vozes.

Bosi, E. (2003). O tempo vivo da memória: ensaios de psicologia social. Ateliê Editorial.

Brzozowski, J., Cucculelli, M., \& Surdej, A. (2014). Transnational ties and performance of immigrant entrepreneurs: the role of home-country conditions. Entrepreneurship \& Regional Development, 26(7-8), 546-573.

Cavedon, N. R., \& Silva Ferraz, D. L. (2005). Representações sociais e estratégia em pequenos comércios. RAE-eletrônica, 4(1).

Closs, L. Q., \& Antonello, C. S. (2011). O uso da história de vida para compreender processos de aprendizagem gerencial. Revista de Administração Mackenzie, 12(4), 44.

Coleman, J. S. (1988). Social capital in the creation of human capital. The American Journal of Sociology, 94.

Corrêa, V. S., \& Vale, G. M. V. (2017). A Dinâmica e a influência das redes sociais para o sucesso empreendedor. Revista Organizações em Contexto, 13(25), 1-19.

Cruz, E. P., Falcão, R. P. D. Q., \& Barreto, C. R. (2017). Estudo exploratório do empreendedorismo imigrante brasileiro em Pompano beach e Orlando-eua. Gestão \& Planejamento-G\&P, 18.

De Castro Lima, Á. E., \& de Castro, A. D. L. B. (2018). Brasileiros nos Estados Unidos-Meio Século (Re) fazendo a América (1960-2010). REMHU-Revista Interdisciplinar da Mobilidade Humana, 26(52), 273-275.

Granovetter, M. (2005). The impact of social structure on economic outcomes. The Journal of Economic Perspectives, 19(1), 33-50.

Granovetter, M. (1973). The strength of weak ties. American Journal of Sociology, 78(6), 1360-1380.

Halter, M. (2007). Cultura econômica do empreendimento étnico: caminhos da imigração ao empreendedorismo. Revista de Administração de Empresas, 47(1), 116-123.

Hite, J. M. (2005). Evolutionary processes and paths of relationally embedded network ties in emerging entrepreneurial firms. Entrepreneurship theory and practice, 29(1), 113-144.

Hite, J. M. (2003). Patterns of multidimensionality among embedded network ties: a typology of relational embeddedness in emerging entrepreneurial firms. Strategic organization,1(1), 9-49.

International Organization for Migration (2017). Measuring Global Migration Potential, 2010-2015. Retrieved from:https://gmdac.iom.int/gmdac-databriefing-measuring-global-migration-potential-20102015

-Light, I. (1972). Ethnic enterprise in America: Business and welfare among Chinese, Japanese, and Blacks. Univ of California Press.

Lima, A. E. C., \& Castro, A. L. B. (2017). Brasileiros nos Estados Unidos: meio século (re)fazendo a América (1960-2010). Brasília: Fundação Alexandre Gusmão.

Lopes, F. T. (2013). Entre o prazer e sofrimento: histórias de vida, drogas e trabalho. Tese (Doutorado em Administração) - Universidade Federal de Minas Gerais, CEPEAD, Belo Horizonte (192 f.).

Marcovitch, J. (2007). Pioneiros e empreendedores: a saga do desenvolvimento no Brasil (Vol. 3). Edusp.

Mariz, M. E. A., \& Bógus, L. M. M. (2013). Empreendedorismo feminino: imigrantes portuguesas em São Paulo. Brasiliana-Journal for Brazilian Studies, 2(2), 477-505.

Martes, A. C. B. (2016). Chegadas e partidas: migrações internacionais no Brasil recente. GVexecutivo, 15(1), 30-33.

Martes, A. C. B., \& Rodriguez, C. L. (2004). Afiliação religiosa e empreendedorismo étnico: o caso dos brasileiros nos Estados Unidos. Revista de Administração Contemporânea, 8(3), 117-140. 
Empreendedorismo Imigrante e Étnico: O Papel das Redes Sociais no Processo Empreendedor de um Imigrante Sírio no Brasil

Miranda, A. R. A., Cappelle, M. C. A., \& Mafra, F. L. N. (2014). Contribuições do método história de vida para estudos sobre identidade: o exemplo do estudo sobre professoras gerentes. Revista de Ciências da Administração, 59-74.

Nazareno, J., Zhou, M., \& You, T. (2018). Global dynamics of immigrant entrepreneurship: Changing trends, ethnonational variations, and reconceptualizations. International Journal

Paulilo, M. Â. S. (1999). A pesquisa qualitativa e a história de vida. Serviço Social em Revista, 2(2), 135148.

Peroni, C., Riillo, C. A., \& Sarracino, F. (2016). Entrepreneurship and immigration: evidence from GEM Luxembourg. Small Business Economics, 46(4), 639-656.

Portes, A. (2003). Conclusion: Theoretical convergencies and empirical evidence in the study of immigrant transnationalism. International migration review, 37(3), 874-892.

Portes, A., Guarnizo, L. E., \& Haller, W. J. (2002). Transnational entrepreneurs: An alternative form of immigrant economic adaptation. American Sociological Review, 278-298.

Portes, A., \& Sensenbrenner, J. (1993). Embeddedness and immigration: Notes on the social determinants of economic action. American Journal of Sociology, 98(6), 1320-1350.

Portes A. (1987). The social origins of the Cuban enclave economy of Miami. Sociol. Perspect, 30:340-72.

Portes, A., \& Zhou, M. (1992). Gaining the upper hand: Economic mobility among immigrant and domestic minorities. Ethnic and Racial Studies, 15(4), 491-522.

Portes, A., \& Zhou, M. (2012). Transnationalism and development: Mexican and Chinese immigrant organizations in the United States. Population and Development Review, 38(2), 191-220.

Sanders, J. M., \& Nee, V. (1996). Immigrant selfemployment: The family as social capital and the value of human capital. American Sociological Review, 61(2), 231-249. Doi: 10.2307/2096333.

Sanders, J. M., \& Nee, V. (1987). Limits of ethnic solidarity in the enclave economy. American Sociological Review, 52(6), 745-773. Doi: $10.2307 / 2095833$.

Sasaki, E. M., \& de Oliveira Assis, G. (2016). Teorias das migrações internacionais. Anais, 1-19.

Silva, J. C. J. (2013). A História das Políticas Migratórias dos Estados Unidos. Textos e Debates, $1(20)$.

Thomas, W. I., \& Znaniecki, F. (1927). The wider community and the role of the press. The Polish Peasant in Europe and America, 2, 1367-397.

Vale, G. M. V., \& Guimarães, L. D. O. (2010). Redes sociais na criação e mortalidade de empresas. RAERevista de Administração de Empresas, 50(3).

Vasconcelos, G. M. R. D., Rezende, S. F. L., Guimarães, L. D. O., \& Fachin, R. C. (2007). Mobilizando relacionamentos e acessando recursos na criação e evolução de novos negócios. Organizações \& Sociedade, 14(41), 113-134.

Wilson, K. L., \& Portes, A. (1980). Immigrant enclaves: An analysis of the labor market experiences of Cubans in Miami. American Journal of Sociology, 86(2), 295-319.

Yin, R. K. (2005). Estudo de caso: planejamento e métodos. (2.ed.). Porto Alegre: Bookman.

Zhou, M. (2004). Revisiting ethnic entrepreneurship: convergencies, controversies, and conceptual advancements. International Migration Review, 38(3), 1040-1074.

\section{SOBRE OS AUTORES}

- Gislene Cordeiro da Silva Diniz - Pontifícia Universidade Católica de Minas Gerais - PUC, Minas Gerais, (Brasil).E-mail: gislenecordeirodiniz@gmail.com Orcid id: https://orcid.org/0000-0002-7509-8263

- Liliane de Oliveira Guimarães - Pontifícia Universidade Católica de Minas Gerais - PUC, Minas Gerais, (Brasil). E-mail: lilianepuc@facile.com.br Orcid. Id: https://orcid.org/0000-0002-3346-2207

- Duval Magalhães Fernandes - Pontifícia Universidade Católica de Minas Gerais - PUC, Minas Gerais, (Brasil). E-mail: duvalfernandes@hotmail.com Orcid. Id: https://orcid.org/0000-0003-2448-8277 
G. C. S. Diniz, L. O. Guimarães \& D. M. Fernandes

\section{IMMIGRANT AND ETHNIC ENTREPRENEURSHIP: THE ROLE OF SOCIAL NETWORKS IN THE ENTREPRENEURSHIP PROCESS OF A SYRIAN IMMIGRANT IN BRAZIL}

Gislene Cordeiro da Silva Diniz, Liliane de Oliveira Guimarães, Duval Magalhães Fernandes Pontifícia Universidade Católica de Minas Gerais - PUC, Minas Gerais, (Brazil).

\section{ARTICLE DETAILS}

\section{Article history:}

Received: 21 August 2018

Accepted: 4 March 2019

Available online April: 01th 2019

Double Blind Review System

Scientific Editor

Ilan Avrichir

\section{Keywords}

Immigrant Entrepreneurship

Ethnic Entrepreneurship

Social networks

Syrian immigrants
ABSTRACT

This study aimed to understand and analyze the role of social networks in the host country in the entrepreneurship of a Syrian immigrant in Brazil. With the use of the life history methodology, we sought to identify and describe the types of resources that are offered by social networks, analyzing the role of these networks in the entrepreneurship of an immigrant. The results confirm studies reported in the literature, that is, social networks represent sources of various types of resources, among them financial, social and human capital and still act as emotional support and counseling that allies favor immigrant and ethnic entrepreneurship. The survey also confirmed that social networks are valuable tools for creating and maintaining new business.

(C) 2018 Internext | ESPM. All rights reserved!

Para citar este artigo:

da Silva Diniz, G., Guimarães, L., \& Fernandes, D. (2019). Empreendedorismo Imigrante e Étnico: O Papel das Redes Sociais no Processo Empreendedor de um Imigrante Sírio no Brasil. Revista Eletrônica de Negócios Internacionais, 14(2), 161-174. doi:http://dx.doi.org/10.18568/internext.v14i2.467 